\title{
Intraempreendedorismo no setor público: Estudo de caso na Universidade Tecnológica Federal do Paraná (UTFPR)
}

Sylvia Bitencourt Valle Marques sylvia@utfpr.edu.br

Universidade Tecrológica Federal do Paraná (UTFPR), Curitiba, Paraná, Brasil.

\section{Vanessa Ishikawa Rasoto}

\section{vrasoto@gmail.com}

Universidade Tecnológica Federal do

Paraná (UTFPR), Curitiba, Paraná, Brasil.

Gerson Ishikawa

gerson.ishikawa@gmail.com

Universidade Tecnológica Federal do

Paraná (UTFPR), Curitiba, Paraná, Brasil.

Leslie de Oliveira Bocchino

leslie@utfpr.edu.br

Universidade Tecnológica Federal do

Paraná (UTFPR), Curitiba, Paraná, Brasil.

\begin{abstract}
RESUMO
Com as mudanças sociais decorrentes das crescentes interdependências culturais e econômicas que ocorrem em âmbito mundial, o empreendedorismo pode contribuir para a sobrevivência das organizações, inclusive aquelas do setor público, favorecendo a agregação de valores aos serviços prestados à sociedade. 0 empreendedorismo tem sido pouco estudado quando se refere ao setor público, de forma que justifica o presente estudo interpretações mais exatas sobre o tema. A pesquisa tem como objetivo investigar a perspectiva dos gestores públicos quanto a importância do empreendedorismo na gestão de uma organização pública. 0 método de pesquisa utilizado foi estudo de caso na Universidade Tecnológica Federal do Paraná, com aplicação de questionários aos seus gestores. Motivou a escolha do objeto de estudo o fato de que as Universidades são apontadas como instituições com papel fundamental no processo de ensinar e difundir o empreendedorismo. Os resultados demonstraram a perspectiva dos gestores pesquisados sobre a importância de características relacionadas ao empreendedorismo na gestão administrativa pública.
\end{abstract}

PALAVRAS-CHAVE:Empreendedorismo. Intraempreendedorismo público. 


\section{INTRODUÇÃO}

A contextualização do presente trabalho inicia-se com o significado do termo "empreendedor" e manifestações no sentido de que o uso do empreendedorismo vem sendo requisitado, há tempos, como ferramenta necessária para enfrentar as mudanças decorrentes da globalização. $O$ termo "empreendedor", do francês entrepreneur, significa "estar pronto para iniciar algo". Drucker, ao ampliar o conceito de Jean-Baptiste Say, conceituando como empreendedor aqueles que se valem das oportunidades para criar mudanças e não se limitam a seus próprios talentos para empreender, mas mobilizam recursos e a experiência de cada um para atingir seus objetivos e gerar avanços. (LORETO; MAZZEO; MACHADO, 2009).

Pinchot III (1989) afirma que em época de mudanças rápidas, tanto econômicas quanto tecnológicas, o espírito empreendedor pode ser uma vantagem única e importante, desde que se aprenda a usá-lo. Neste sentido, a opinião de Alencar (1998), para quem devido à globalização, competição no ambiente de negócios e ritmo acelerado da mudança, as organizações têm sido pressionadas a fazer um melhor uso de seus recursos disponíveis, incluída a criatividade de seus recursos humanos. Há um reconhecimento crescente de que a criatividade é um fator chave para a inovação e sucesso a longo prazo das organizações.

Para Feger, Fischer e Nodari (2009), "a necessidade de competição e inovação das organizações, para fazer frente aos efeitos da globalização, tem reavivado as discussões sobre o empreendedorismo".

O fenômeno empreendedorismo já foi mais reservado ao setor privado, mas atualmente tem despertado o interesse do setor público, como forma de gerir a escassez de recursos, inovar e renovar as organizações públicas. Matias-Pereira (2010) entende que as mudanças de paradigmas advindas da globalização, e que abrangem todas as áreas - política, econômica, social, cultural, tecnológica, ambiental, estão reverberando na humanidade toda e, consequentemente, no Estado, de forma a exigir deste a construção de um novo modelo de Estado e de gestão pública.

O empreendedorismo público não toma a forma de empreendedorismo individual, mas de intraempreendedorismo ou empreendedorismo corporativo, isto é, sempre agindo dentro de uma organização já existente. Manifesta-se em uma variedade de atividades, tais como a mudança do ambiente institucional ou regras do jogo, criação de novas organizações públicas e criação e gestão de novos recursos públicos. Essas atividades envolvem a criação de recursos públicos e a tomada de decisões sobre alocação de tais recursos. Inovação no interesse público ocorre quando esses recursos são utilizados em novas formas baseadas em novas ideias sobre a sua relevância para o interesse público ou de novos mecanismos para a sua implementação. (KLEIN et al., 2010).

O empreendedor público, hoje, dispõe de condições que o permite atuar como agente de transformação social, como pessoa que contribui para o aumento da capacidade de oferecer serviços e agregar valor à organização pública, por meio da maximização de eficiência na prestação dos serviços que oferece à sociedade. Para Salviet al. (2007), o ensino do empreendedorismo aparece no contexto em que a oferta de trabalho, em seu formato tradicional, 
diminui. Assim torna-se de grande importância a formação de novos empreendedores, o que poderá ocorrer por meio de instituições de ensino.

Assim, devido à globalização, à concorrência por ela gerada e as mudanças em ritmo acelerado da atualidade, as organizações sofrem a demanda por inovação e espírito empreendedor para sobreviver. Isto tem acarretado maior necessidade de se estudar o empreendedorismo em suas diversas facetas.

O objetivo desta pesquisa foi verificar o grau de importância que os gestores de uma instituição pública de ensino superior dão a características relacionadas ao empreendedorismo no dia a dia de sua gestão. A pesquisa limitou-se à Universidade Tecnológica Federal do Paraná (UTFPR), usando como unidade pesquisada a Reitoria da Universidade. Motivou a escolha do objeto de estudo o conhecimento da estrutura da instituição e a facilidade para contatar os pesquisados.

No que tange à metodologia, trata-se de estudo de caso aplicado em uma instituição pública de ensino superior com característica multicampus (UTFPR Universidade Tecnológica Federal do Paraná com campus em 13 cidades do Estado do Paraná), utilizando abordagem fundamentada em questionários.

Ao final da pesquisa, deverá ser possível responder se os gestores públicos da UTFPR, no âmbito da Reitoria dão importância a características que se relacionam ao empreendedorismo dentro da organização em que atuam.

\section{MARCO TEÓRICO}

Durante a última década tem havido importantes avanços teóricos e empíricos sobre empreendedorismo. Estes avanços foram obtidos por estudiosos em disciplinas como Economia, Geografia e Sociologia, para proporcionar uma melhor compreensão do desenvolvimento econômico em nível regional. É possível observar os avanços na qualidade dos dados e da sofisticação da análise estatística. Embora a qualidade dos dados e análises tenha melhorado ao longo do tempo, os avanços foram feitos por disciplinas tradicionais. Isso é bem ilustrado pelo fato de que existe incorporação dos conceitos de empreendedorismo em funções de produção econômica. (ACS; STOREY, 2004). Neste sentido, tem-se que o empreendedorismo não é um evento único, mas um processo, e deriva de disciplinas já estabelecidas como economia, ciências do comportamento e sociologia, as quais podem explicar muito de seus aspectos, de acordo com Baron e Shane (2010).

Filion (2003) refere-se ao empreendedorismo como sendo um campo de estudo, já que não existe um paradigma absoluto, ou um consenso científico. É um domínio específico, não uma disciplina acadêmica com o sentido que se atribui habitualmente a qualquer outra já consolidada. Traduz-se num conjunto de práticas capazes de garantir a geração de riqueza e um melhor desempenho às sociedades. Porém, não existe teoria absoluta a este respeito. É visto, muitas vezes, como um fenômeno individual, mas empreendedorismo é um fenômeno social e exprime-se nas sociedades a partir de valores relativamente consensuais e constrói-se em torno do que é valorizado numa sociedade.

Paiva Jr. e Guerra (2010) entendem que "o empreendedorismo não poder ser encerrado em uma definição universal, uma vez que isso não traduz a 
complexidade do fenômeno", de forma que o uso de um conceito que envolva o empreendedor, a empresa e o ambiente, isto é, multidimensional, é válido por "representar uma concepção mais ampliada do assunto e por renunciar ao formato reducionista de compreensão do fenômeno apenas como prática de abertura de empresa." Quanto à análise do empreendedorismo, ponderam os autores que ela "exige a integração de três níveis: o empreendedorismo como fenômeno, o empreendedor como ator, e a organização impulsionada pelo ator empreendedor."(PAIVA JR.; GUERRA, 2010).

Na opinião de Souza, Fracasso e Lopez Júnior (2008), como são vários os conceitos de empreendedorismo e diversos os estudos a fim de identificar suas características, bem como o comportamento do empreendedor, existe uma ausência de definição consensual do empreendedor. Para Da Costa, Barros e Carvalho (2011), o conceito de empreendedorismo assume significados diversos, dependendo de seu contexto e uso.

Lévesque (2005) discorre sobre as contribuições teóricas de Cantillon, de Weber e de Schumpeter, citando que para Cantillon, o empreendedor é o homem racional por excelência, pois opera numa sociedade onde tudo se regula pela concorrência de mercado, em que se deve saber avaliar o provável. Isto é, o empreendedor deve ser racional, para saber calcular os riscos. Refere-se ainda a Weber, para quem o empreendedor está longe de ser racional, na medida em que seu empreendimento se baseia numa acumulação de excedentes, acima de suas próprias necessidades, e que se recusa a viver a vida para se dedicar a seu projeto. Por fim, ressalta que para Schumpeter o empreendedor não é puramente utilitarista e racional, pois é um líder que busca ir além das limitações usuais e caracteriza-se positivamente pela inovação. A opinião de Feger, Fischer e Nodari sobre as características da figura do empreendedor:

Pode-se concluir que os empreendedores têm uma postura diferenciada ante os desafios. São indivíduos criativos e que, por meio do esforço pessoal, criam novas oportunidades; isso ocorre tanto dentro de uma organização, no caso do empreendedor corporativo, quanto na criação de negócios próprios. (FEGER; FISCHER; NODARI, 2009).

No que tange à criatividade, Baron e Shane (2010) fazem distinção entre "geração da ideia" e "criatividade". Enquanto que o primeiro caso refere-se a "produção de ideia para algo novo", a criatividade consubstancia-se em uma geração de ideia que, além de nova, é potencialmente útil.

Para Wolf et al. (2001), os empreendedores "são pessoas corajosas, que assumem riscos calculados e sabem gerenciar esses riscos, são líderes e são admirados pelos funcionários pelo modelo adotado de empreender, pois ele sabe valorizar, recompensar e estimular a equipe."

Schmidt e Bohnenberger (2009), em estudo para propor um modelo de medição para o perfil e a intenção empreendedora, relacionando-os com o desempenho organizacional, definiu as seguintes características do empreendedor: auto-eficácia, capacidade de assumir riscos calculados, planejador, detecta oportunidades, persistência, sociável, inovação e liderança.

"O mito de que o empreendedor é um ser nato acabou, pois atualmente acredita-se que o processo empreendedor pode ser ensinado e compreendido 
por qualquer pessoa."(LAGO et al, 2008). Corrêa e Bêrni (2000) advertem que muitos estudiosos vêm procurando distinguir a figura do empreendedor por suas atribuições e qualidades. Porém, "torna-se praticamente impossível realizar uma descrição universalmente aceita tanto no que diz respeito ao agente considerado como empreendedor, como também em relação a suas ações." (CORRÊA; BÊRNI, 2000).

"Assim como as empresas privadas, as organizações públicas também têm necessidade de realizar inovações." (TINOCO, 2012). O empreendedorismo público está relacionado a instituições que podem solucionar conflitos associados ao uso comum de recursos naturais (FEGER; FISCHER; NODARI, 2009).

Mierlo (1995) diz que atualmente o setor público já não é um sistema fechado, mas se abrindo de forma que se envolve em relações de troca contínua com o meio ambiente, o qual inclui o sistema político e todos os atores que o compõe. Os cidadãos funcionam como os consumidores dos serviços e produtos fornecidos pelo governo. Assim, a gestão externa do governo torna-se mais importante. Para Meza (2012), "tanto o empreendedor privado quanto o público percebem uma lacuna entre o resultado ou desempenho atual e o potencial; e identificam os recursos relacionados a este resultado" (MEZA, 2012).

O empreendedorismo público, nesta pesquisa, será analisado sob os aspectos da organização (empreendedorismo corporativo ou intraempreendedorismo). No contexto de que empreendedor é quem exerce o controle sobre a produção, pode estar presente em uma organização que não seja sua. Isto, em contraponto à ideia de que empreendedorismo está ligado tão somente à criação de novas empresas. Está evidenciado que o empreendedorismo "está ligado mais ao modo de ser do que a empreendimentos de qualquer natureza, e este modo de ser se aplica a qualquer pessoa independente de ser proprietário ou colaborador das organizações, neste caso chamado de intra-empreendedor" (SALVI et al., 2007).

Entendem Salviet al (2007) que o espírito empreendedor é uma característica distinta, podendo estar presente em uma pessoa ou em uma instituição. Para Prado et al. (2011), intraempreendedor pode também ser chamado de empreendedor corporativo e "são pessoas capazes de ver diferente, ou seja, ver o invisível ou o que as pessoas não conseguem visualizar de uma determinada situação ou problema, e transformar em oportunidade de negócios mais rentáveis."

Complementam que o intraempreendedorismo, decorrente do empreendedorismo, surge como reação positiva para enfrentar os atuais desafios empresariais, de forma que a própria empresa assume "o desafio de desenvolver seus colaboradores de maneira que os mesmos desenvolvam suas ideias e as realizem." (PRADO et al., 2011). Esclarecem ainda sobre as características básicas dos intraempreendedores, que "são parecidas com as dos empreendedores e possuem base nas necessidades, aptidões, conhecimentos e valores." (PRADO et al., 2011).

Com base no fato de que o empreendedorismo tem três diferentes abordagens (o resultado da ação do empreendedor, as características do empreendedor e o comportamento do empreendedor), Tinoco (2012) entende que o empreendedorismo "pode ser visto de uma forma mais ampla, não se limitando à atuação de um empreendedor individual", de forma que as inovações 
podem resultar do trabalho dentro das organizações. Para o autor, o perfil empreendedor da organização é influenciado pela capacidade de explorar oportunidades que seus empregados têm. Assim, dentro da organização, "o grau de empreendedorismo dependente da atitude de muitos indivíduos dentro da organização, ou seja, não depende apenas da atitude dos executivos no topo da hierarquia organizacional" (TINOCO, 2012).

Resumidamente, o foco do empreendedorismo organizacional é "a identificação e exploração de oportunidades com o objetivo de aumentar as receitas e prover o crescimento das empresas" (TINOCO, 2012).

O termo intraempreendedorismo foi cunhado na década de 1980 por GiffordPinchot III, para quem os intraempreendedores são todos os sonhadores que realizam. Intraempreendedorismo também surge como uma forma de reter os talentos dentro das empresas e ao mesmo tempo lidar de forma mais eficaz com as ameaças do mercado concorrente (CHIEH; ANDREASSI, 2007).

Para Alencar (1998), as organizações vêm sofrendo uma enorme pressão para se manterem em um processo permanente de inovação. Como a origem da inovação reside nas ideias criativas dos indivíduos, a criatividade tem recebido uma atenção crescente. Ela tem sido apontada como uma habilidade humana crítica, que deve ser canalizada e fortalecida a favor do sucesso da organização. Cabe aos dirigentes estar atentos às condições prevalentes no seu ambiente de trabalho, no sentido de desfazer possíveis barreiras à criatividade, maximizando as oportunidades para a sua expressão. Muitas organizações tendem a ignorar o potencial para a competência, responsabilidade e produtividade, estimulando mais a dependência e a passividade do que a iniciativa e a criatividade. As necessidades básicas de reconhecimento, apoio e segurança, que deveriam ser atendidas no ambiente de trabalho, são, muitas vezes, ignoradas, afetando a motivação para o trabalho e contribuindo para manter adormecido o potencial para a criatividade. Dentre os requisitos que caracterizam uma organização criativa, salientam-se especialmente a presença de líderes criativos e o cultivo de um ambiente criativo. Caberia aos líderes imprimir as condições que facilitariam a emergência das ideias criativas, promovendo um ambiente de abertura e apoio às ideias inovadoras.

As qualidades do ambiente que promovem a criatividade: liberdade e controle, estilo de gerenciamento, flexibilidade, recursos para se colocar a ideia em prática, apoio do grupo de trabalho, encorajamento, reconhecimento e feedback, tempo adequado para realização das tarefas. Os fatores que bloqueiam a criatividade: clima organizacional pobre, excesso de avaliação e pressão, recursos insuficientes, ênfase no status quo, pressão de tempo, competição acirrada e projeto inadequado de gerenciamento (ALENCAR, 1998).

Alencar (1998) propõe um modelo de inovação organizacional com três componentes básicos: Recursos: dizem respeito a fundos, materiais, pessoas e informações disponíveis para se realizar o trabalho; técnicas: incluem competências no gerenciamento da inovação, presentes nos distintos níveis da organização; e motivação: é o componente mais importante, tanto no âmbito do indivíduo quanto da organização. A motivação é o elemento catalisador das ações voltadas para a inovação. Segundo ela, as características de uma organização que se constituem como estímulos à criatividade no ambiente de 
trabalho são: Suporte da organização; estrutura organizacional; apoio da chefia; e suporte do grupo de trabalho.

Conclui Alencar (1998) que é necessário que uma plataforma para a criatividade individual esteja presente no ambiente das organizações. Ela tem como base a presença de sentimentos de confiança e respeito, a harmonia nas equipes, a prática das virtudes de compartilhar ideias, respeitar as diferenças, valorizar o trabalho do indivíduo e do grupo, reconhecer as potencialidades e oferecer oportunidades para a produção e fertilização de ideias.

A função básica do intraempreendedor, na visão de Pinchot III (1989), é conceber visões de negócios e transformá-las em realidades de negócios. Esta visão tem duas partes: A primeira, que é a descoberta intuitiva de um padrão potencial de negócio, e a segunda, crucial, que é o trabalho de planejamento do negócio. As duas partes não podem ser construídas em sequência e se alternam entre o criativo e o analítico.

Ressalta Pinchot III (1989) que as organizações produzem muitas boas ideias, mas em geral são incapazes de implementá-las. Ou as grandes corporações encontram formas de tornar o intraempreendedorismo mais recompensador, ou perderão seus melhores inovadores. Pois haverá um número, rapidamente crescente, de novos e sofisticados concorrentes para todo ou parte de qualquer negócio, e os melhores indivíduos de uma corporação sairão dela para se tornarem empreendedores. As corporações estão percebendo a necessidade de intraempreendedores; a explosão de informações está encorajando as empresas a abandonarem os sistemas hierárquicos em favor de outros, em que os inovadores ajam em pé de igualdade com os que formam um sistema informal de apoio.

Segundo Drucker (2002), "para permanecer no negócio, a grande organização precisa inovar." Ressalta Pinchot III (1989) que ou as grandes corporações encontram formas de tornar o intraempreendedorismo mais recompensador, ou perderão seus melhores inovadores. Defende que as grandes empresas contam com recursos que podem tornar o desenvolvimento de uma nova ideia muito mais fácil para um intraempreendedor, do que seria para um empreendedor, com as seguintes vantagens: poder de marketing, base tecnológica, pessoas em quem se pode confiar, vantagem de redes limitadas, fábrica piloto e produção em tempo partilhado e finanças. Como desvantagens, o autor cita o poder de decisão, investidores sofisticados e propriedade.

Sobre os fatores da liberdade para examinar o ambiente da empresa quanto ao intrapreendedorismo, ensina Pinchot III (1989) que os fatores de liberdade são uma forma de gerenciar de forma a olhar o problema de baixo para cima, e de se considerar o que as pessoas que efetivamente executam o trabalho, em especial os de inovação, necessitam para prosseguir. A importância das recompensas ao longo da carreira do intraempreendedor (reconhecimento, créditos múltiplos, promoção, gerência, bônus e liberdade financeira), também é abordada pelo autor, segundo o qual esta questão já preocupa as corporações. A medida mais fundamental de progresso para o intraempreendedor é a crescente liberdade para usar recursos corporativos para construir novos negócios para a corporação. O capital é uma forma mensurável de liberdade para assumir riscos e construir um negócio forte. $O$ equivalente a isto, no cenário corporativo, é o intracapital. Intracapital é um orçamento ganho pelo intraempreendedor e usado para 
financiar novos intraempreendimentos e inovações para a corporação. É um sistema de recompensa pouco usual e pode ser um poderoso motivador (dá aos intraempreendedores liberdade para fazer suas ideias acontecerem), embora possa ter um custo negativo (ele talvez seja gasto com mais cuidado que o dinheiro que é parte do orçamento de um alto gerente). Para os intraempreendedores, intracapital significa liberdade. Conclui o autor que, para sobreviver, a corporação do futuro deve mudar radicalmente, em relação à corporação de hoje. O futuro é intraempreendedor, não só porque esta é uma forma de se aumentar o nível de inovação e de produtividade das organizações, mas uma forma de se organizar grandes empresas, de modo que o trabalho volte a ser uma expressão alegre da contribuição da pessoa à sociedade.

Para Chieh e Andreassi (2007), as organizações modernas adotam medidas para reduzir seus custos e elevar o nível de qualidade de seus produtos e serviços; mas estudiosos de assuntos ligados à competitividade empresarial vêm apontando a relevância da inovação na formação de vantagens competitivas das empresas. Eles consideram a criação de um ambiente intraempreendedor como fator chave para estimular a inovação e, consequentemente, alcançar o sucesso empresarial. É um grande desafio para as empresas manterem o espírito empreendedor de seus funcionários na medida em que elas crescem, se estabilizam e alcançam certo grau de sucesso, porque algumas condições que propiciam o intraempreendedorismo são neutralizadas no processo de expansão, em que a organização aumenta o número de funcionários, introduz novas camadas de gerenciamento, novas estruturas, novas políticas e novos procedimentos operacionais.

Os gestores ainda enxergam um potencial conflito de interesse entre a corporação e os funcionários ávidos em desenvolver seu "projeto pessoal" dentro da empresa. Eles entendem que um funcionário não conseguiria dedicar-se à empresa tendo essa ideia e ambição. Esta falsa dicotomia ou aparente conflito de interesses entre empresa e funcionário empreendedor, foi desfeita por Pinchot III na década de oitenta. O conceito de intraempreendedorismo criado por ele abriu um caminho alternativo para o melhor aproveitamento dos recursos humanos que as empresas possuem. (CHIEH; ANDREASSI, 2007). David, Carvalho e Penteado (2011) alertam que o desenvolvimento organizacional "depende também da capacidade da empresa de conquistar, reter, aplicar, formar, motivar e recompensar seus colaboradores".

Para Hashimoto (2009) muitas são as oportunidades, numa organização, para se explorar a inovação, que pode ser em produtos ou serviços, processos ou modelos de negócios. Para o autor, "qualquer mudança em processos internos ligados ou não aos produtos e serviços que otimizam o uso de recursos, facilitam o processo de decisão ou reduzem custos", configura-se numa forma de inovação.

Para que ocorra a inovação, a organização deve ter flexibilidade, pois sem ela não há a geração de mudanças inerente ao processo inovador e deve ter a capacidade de aproveitar oportunidades identificadas (HASHIMOTO, 2009).

Em síntese é possível apresentar o seguinte Quadro 1, com características inerentes à organização empreendedora. 


\begin{tabular}{|c|c|}
\hline Características presentes na organização empreendedora & $\begin{array}{l}\text { Referência } \\
\text { teórica }\end{array}$ \\
\hline $\begin{array}{l}\text { A característica "espírito empreendedor" pode referir-se não só à } \\
\text { pessoa, como também à organização. }\end{array}$ & $\begin{array}{l}\text { Salviet al. } \\
(2007)\end{array}$ \\
\hline $\begin{array}{l}\text { A capacidade de transformar um problema em oportunidade de } \\
\text { negócios também é característica do intraempreendedorismo. }\end{array}$ & $\begin{array}{l}\text { Prado et al. } \\
\qquad(2011)\end{array}$ \\
\hline $\begin{array}{l}\text { O empreendedorismo, visto de forma mais ampla, possibilita que as } \\
\text { inovações sejam resultado de trabalho dentro da organização. }\end{array}$ & Tinoco (2012) \\
\hline A criatividade pode ser característica da organização. & Alencar (1998) \\
\hline $\begin{array}{l}\text { Recursos, técnicas e motivação são elementos de um modelo de } \\
\text { inovação organizacional. }\end{array}$ & Alencar (1998) \\
\hline $\begin{array}{l}\text { Para haver inovação, as ideias devem ser implementadas, o que } \\
\text { requer planejamento por parte do intraempreendedor, }\end{array}$ & $\begin{array}{l}\text { Pinchot III } \\
\text { (1989) }\end{array}$ \\
\hline $\begin{array}{l}\text { Capacidade de aproveitar oportunidades e flexibilidade são } \\
\text { características de uma organização empreendedora. }\end{array}$ & $\begin{array}{l}\text { Hashimoto } \\
\text { (2009) }\end{array}$ \\
\hline
\end{tabular}

Fonte: Elaborado pelos autores.

Importa ressaltar que este rol não é exaustivo, uma vez que todas as características relacionadas ao indivíduo empreendedor relacionam-se também à organização empreendedora. Resumem Corrêa e Bêrni que "o empresário inovador precisa de um meio inovador, nomeadamente, a firma inovadora" (CORRÊA; BÊRNI, 2000).

Por fim, ressalte-se que o empreendedorismo numa organização pública "pode ser caracterizado pelo modelo incremental, pois se traduz em melhoria paulatina de métodos e procedimentos administrativos; em outras palavras, pode ser constatado por meio do aumento da efetividade." (COELHO, 2010).

\section{METODOLOGIA}

A pesquisa foi aplicada a um estudo de caso em uma instituição pública de ensino superior, qual seja a Universidade Tecnológica Federal do Paraná - UTFPR, utilizando uma abordagem fundamentada em questionários. Os pesquisados pertencem à estrutura central, a Reitoria, da UTFPR. Ressalte-se, aqui, que não faz sentido estabelecer hipóteses, a priori, uma vez que estudo de caso foi o método escolhido.

No que tange ao tratamento de dados, as respostas do questionário foram tabuladas e tratadas de forma quantitativa. Para a consecução da pesquisa foi elaborada uma listagem dos gestores vinculados à Reitoria da UTFPR. O questionário foi enviado para tais gestores da Reitoria da Universidade, não só aos Pró-Reitores como para seus Adjuntos, bem como optou-se por mandar ao Reitor e também seu Vice, de forma que na impossibilidade de obter a resposta de um deles, a área não ficaria sem participar da pesquisa. Todas as áreas enviaram respostas, sendo que o questionário foi respondido por 25 gestores do Sistema, do total de 31 questionários enviados.

Observe-se que para este trabalho adotou-se o conceito de Gestor Público constante do glossário da Câmara dos Deputados (Congresso Nacional Brasileiro), qual seja o "funcionário público, ocupante do cargo de carreira, ou agente de empresa estatal que pratica atos de gestão, administra negócios, bens ou 
serviços" (Disponível em: <www2.camara.leg.br/glossario/g.html>. Acesso em: 25.jun.2013).

Como instrumentos, foram utilizadas fontes bibliográficas e aplicações de questionários com questões predominantemente fechadas. A coleta de dados se deu por meio do envio de questionários por mensagem eletrônica a cada um dos pesquisados.

O questionário aborda questões com o intuito de verificar o valor que os gestores dão a atributos essenciais nos empreendedores e nos ambientes onde ele se desenvolve. O questionário baseou-se em respostas de escala de Likert, onde os pesquisados assinalaram seu grau de concordância com uma afirmação, numa escala de cinco opções.

As exceções a esse modelo de pergunta foram uma questão de múltipla escolha a respeito dos mecanismos de capacitação oferecidos pela instituição pesquisada e outras abertas (e opcionais) para o relato de exemplos e observações a respeito do questionário.

Há questão que refere-se à importância da presença de instrumentos de inovação nas universidades, de forma que se possa disseminar o conhecimento relativo à inovação e ao empreendedorismo. Ressaltam essa importância, Costa Barbosa e Silva (2011); Salviet al. (2007) e Filion (2003).

Para o cumprimento do objetivo de "verificar o grau de importância que os gestores de uma instituição pública de ensino superior dão a características relacionadas ao empreendedorismo", foram feitas questões que buscam investigar qual a importância que os investigados dão a características relacionadas ao empreendedorismo, ao empreendedor, ao intraempreendedor ou à organização empreendedora, conforme demonstrado no marco teórico.

Observe-se que as características não se prendem ao empreendedor individual, podendo estar presentes na organização empreendedora, conforme pode-se observar pelas citações de vários autores - Salviet al. (2007), Prado et al. (2011), Alencar (1998) e Tinoco (2012) - no marco teórico, em especial no item que trata do empreendedorismo sob o foco da organização.

Assim, cada uma das características está relacionada ao empreendedorismo, ao empreendedor, ao intraempreendedor ou à organização empreendedora, conforme demonstrado no marco teórico. A seguir o Quadro 2, com a listagem das características e suas referências no marco teórico:

Quadro 2 - Lista de características relacionadas ao empreendedorismo

\begin{tabular}{|c|c|}
\hline Característica & Citada pelos seguintes autores \\
\hline Liderança & Schmidt e Bohnenberguer (2009) \\
\hline Persistência & $\begin{array}{l}\text { Schmidt e Bohnenberguer (2009); Feger, } \\
\text { Fischer e Nodari (2009) }\end{array}$ \\
\hline Sabe trabalhar em equipe & $\begin{array}{l}\text { Baron e Shane (2010); Alencar (1998); Wolf et } \\
\text { al.(2011) }\end{array}$ \\
\hline Criatividade & $\begin{array}{c}\text { Baron e Shane (2010); Alencar (1998); David, } \\
\text { Carvalho e Penteado (2011) }\end{array}$ \\
\hline Motivação para realizar/ Auto-eficaz & $\begin{array}{l}\text { Schmidt e Bohnenberguer (2009); David, } \\
\text { Carvalho e Penteado (2011); Lago et al. } \\
\text { (2008); Salviet al. (2007); Alencar (1998) }\end{array}$ \\
\hline
\end{tabular}




\begin{tabular}{|c|c|}
\hline Característica & Citada pelos seguintes autores \\
\hline Orientação por objetivos ou metas & David, Carvalho e Penteado (2011) \\
\hline Visão sistêmica/estratégicaPlanejador & $\begin{array}{c}\text { Schmidt e Bohnenberguer (2009); Lago et al. } \\
\text { (2008); Corrêa e Bêrni (2000); Lévesque } \\
\text { (2005) }\end{array}$ \\
\hline $\begin{array}{l}\text { Flexibilidade/sociabilidade } \\
\text { Sabe respeitar as diferenças }\end{array}$ & $\begin{array}{l}\text { Schmidt e Bohnenberguer (2009); Baron e } \\
\text { Shane (2010); Alencar (1998) }\end{array}$ \\
\hline Inovador & $\begin{array}{c}\text { Schmidt e Bohnenberguer (2009); David, } \\
\text { Carvalho e Penteado (2011); Lévesque (2005); } \\
\text { Meza (2012) }\end{array}$ \\
\hline Capaz de assumir riscos & $\begin{array}{c}\text { Schmidt e Bohnenberguer (2009); Feger, } \\
\text { Fischer e Nodari (2009); Wolf et al. (2011); } \\
\text { Lago et al. (2008); Lévesque (2005); Meza } \\
\text { (2012) }\end{array}$ \\
\hline Busca ou detecta oportunidades & $\begin{array}{l}\text { Schmidt e Bohnenberguer (2009); Feger, } \\
\text { Fischer e Nodari (2009); Baron e Shane } \\
\text { (2010); Lago et al. (2008); Corrêa e Bêrni } \\
\text { (2000); Meza (2012) }\end{array}$ \\
\hline
\end{tabular}

Fonte: Elaborado pelos autores.

Uma questão refere-se à importância das características na gestão, enquanto que a outra dirige seu foco para as características na pessoa do gestor público.

Cabe ressaltar que esta última elencou itens distintos dos demais, mas que se relacionam também ao empreendedorismo, sendo uma forma diferente de perguntar as mesmas coisas. Exemplificando, não se contentar com o status quo relaciona-se tanto com espírito inovador, quanto com inovação; gestão participativa e comunicação aberta e frequente, com capacidade de trabalhar em equipe; gerenciar conflitos e bom relacionamento, com flexibilidade.

Ainda neste ponto do marco teórico e considerando que para Tidd, Bessant e Pavitt (2008), a gestão da inovação é uma capacidade aprendida, o questionário aplicado apresenta questão que tem como objetivo averiguar em que áreas a instituição pesquisada propicia mecanismos de capacitação.

No que se refere à delimitação do trabalho, a pesquisa limitou-se à Universidade Tecnológica Federal do Paraná (UTFPR), usando como unidade pesquisada a Reitoria da Universidade.

Há que se considerar também tratar-se de um estudo de caso, motivo pelo qual os resultados obtidos não devem ser generalizados.

Motivou a escolha do objeto de estudo o conhecimento da estrutura da instituição e a facilidade para contatar os pesquisados.

\section{RESPOSTAS DOS GESTORES}

A questão ora analisada objetiva averiguar que grau de contribuição determinados itens poderiam alcançar na gestão dos pesquisados. A escala usada para pergunta: nenhum potencial; baixo potencial; potencial razoável; grande potencial; e alto potencial. Os resultados estão apresentados em tabelas. 
Sobre o grau de contribuição potencial dos itens, tem-se a Tabela 1, onde os itens foram colocados na ordem decrescente, considerando a soma das opções "alto potencial" e "grande potencial":

Tabela 1 - Porcentagem de respostas dos gestores do Sistema sobre o potencial de contribuição de cada um dos seguintes itens na gestão

\begin{tabular}{|c|c|c|c|c|c|}
\hline & $\begin{array}{l}\text { Nenhum } \\
\text { potencial }\end{array}$ & $\begin{array}{c}\text { Baixo } \\
\text { potencial }\end{array}$ & $\begin{array}{l}\text { Potencial } \\
\text { razoável }\end{array}$ & $\begin{array}{l}\text { Grande } \\
\text { potencial }\end{array}$ & $\begin{array}{c}\text { Alto } \\
\text { potencial }\end{array}$ \\
\hline $\begin{array}{c}\text { Cooperação com outras } \\
\text { Universidades }\end{array}$ & 0 & 16 & 4 & 36 & 44 \\
\hline $\begin{array}{c}\text { Cooperação entre } \\
\text { pesquisadores e pessoal } \\
\text { administrativo da própria } \\
\text { instituição }\end{array}$ & 8 & 8 & 8 & 28 & 48 \\
\hline $\begin{array}{c}\text { Cooperação entre } \\
\text { pesquisadores e pessoal } \\
\text { administrativo de outras } \\
\text { instituições }\end{array}$ & 8 & 8 & 8 & 40 & 36 \\
\hline $\begin{array}{l}\text { Cooperação com órgãos de } \\
\text { fomento }\end{array}$ & 8 & 16 & 4 & 36 & 36 \\
\hline $\begin{array}{l}\text { Participação dos gestores em } \\
\text { programas de qualificação } \\
\text { para a atividade inovadora }\end{array}$ & 4 & 8 & 20 & 20 & 48 \\
\hline $\begin{array}{l}\text { Cooperação com a } \\
\text { comunidade local }\end{array}$ & 12 & 12 & 12 & 28 & 36 \\
\hline Eventos com servidores & 12 & 12 & 16 & 32 & 28 \\
\hline $\begin{array}{c}\text { Cooperação com empresas } \\
\text { do setor privado }\end{array}$ & 4 & 20 & 24 & 24 & 28 \\
\hline NIT & 16 & 20 & 20 & 12 & 32 \\
\hline Eventos com alunos & 24 & 16 & 20 & 28 & 12 \\
\hline $\begin{array}{l}\text { Programas de } \\
\text { empreendedorismo e } \\
\text { inovação }\end{array}$ & 20 & 28 & 32 & 4 & 16 \\
\hline
\end{tabular}

Fonte: Elaborada pelos autores.

Os itens considerados com maior potencial são cooperação com outras universidades, cooperação entre pesquisadores e pessoal administrativo da própria instituição e de outras instituições.

De qualquer forma, no geral os pesquisados entendem que o grau de contribuição de cada um dos itens pode ser muito mais elevado que aquela ocorrida atualmente na gestão administrativa. 
Atualmente $40 \%$ dos respondentes entende que os programas de empreendedorismo e inovação não afetam sua gestão; considerando o potencial destes programas, a porcentagem dos que continuam considerando isso diminui pela metade (20\%). O mesmo ocorre com os NITs (Núcleos de Inovação Tecnológica), que $32 \%$ responderam como não contribuindo para sua gestão atualmente e somente $16 \%$ mantiveram a resposta quando se trata do potencial de contribuição que tais Núcleos podem vir a ter.

Desta forma, os itens elencados, quais sejam os programas de empreendedorismo e inovação, eventos com alunos, eventos com servidores, núcleos de inovação tecnológica, cooperação com outras Universidades, com empresas do setor privado, com órgãos de fomento, com a comunidade local, entre pesquisadores e pessoal administrativo de outras instituições e da própria instituição, tem potencial para influir de forma mais positiva a gestão pública administrativa no órgão pesquisado.

Esta mesma questão incluiu um item sobre o grau de contribuição que pode vir a ter a participação dos gestores em programas de qualificação que favoreçam a atividade inovadora. Apenas $4 \%$ entendem que não há potencial algum nisso e $8 \%$ que esse potencial é baixo. $48 \%$ dos pesquisados entendem que o potencial é alto, $20 \%$ que é grande e $20 \%$ que é razoável. O Gráfico 1 desenha as respostas:

Gráfico 1 - Potencial de contribuição da participação dos gestores em programas de qualificação para a atividade inovadora

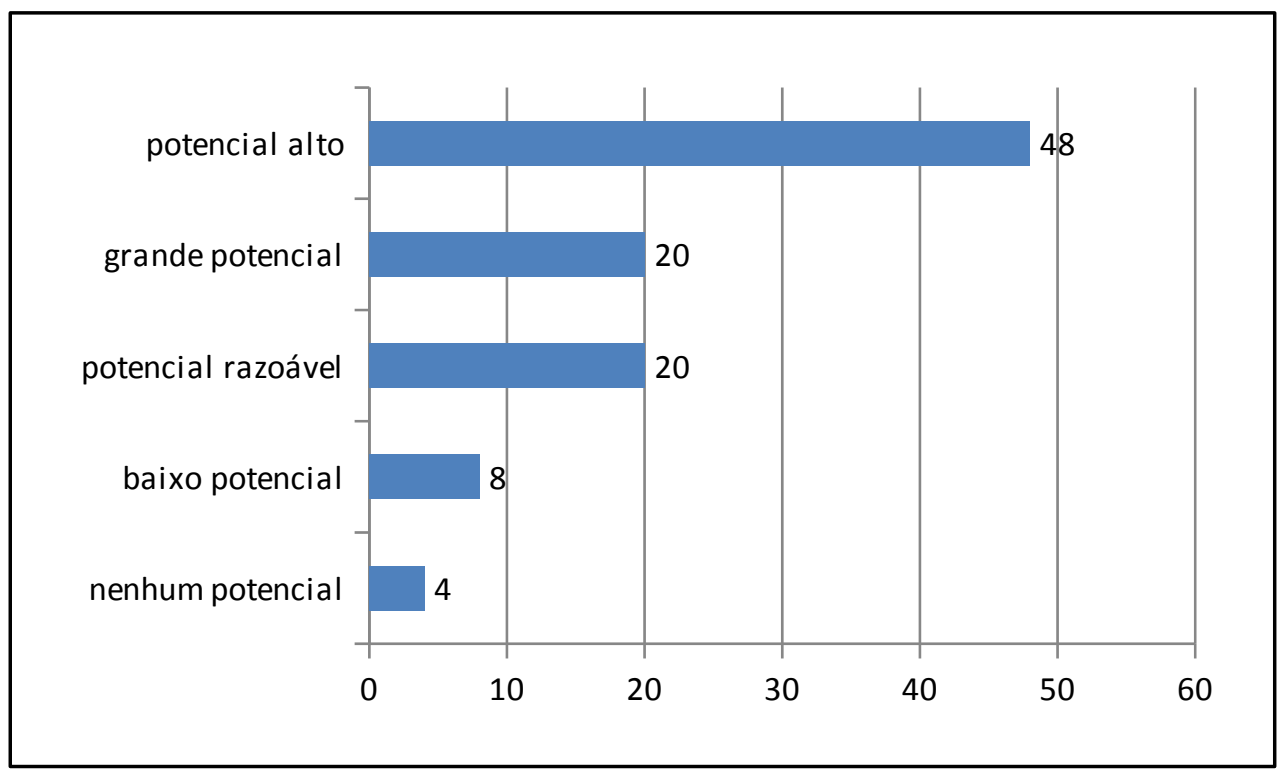

Fonte: Elaborado pelos autores.

Observa-se, então, que para os pesquisados, pode ter uma contribuição positiva em sua gestão qualificar-se em áreas que promovam a atividade inovadora.

Não obstante esta resposta, sobre os mecanismos de capacitação atuais para os gestores, os pesquisados apontaram, conforme se pode observar no Gráfico 2, que são estas as áreas em que mais se capacitam: 
Gráfico 2- Mecanismos de capacitação para os gestores

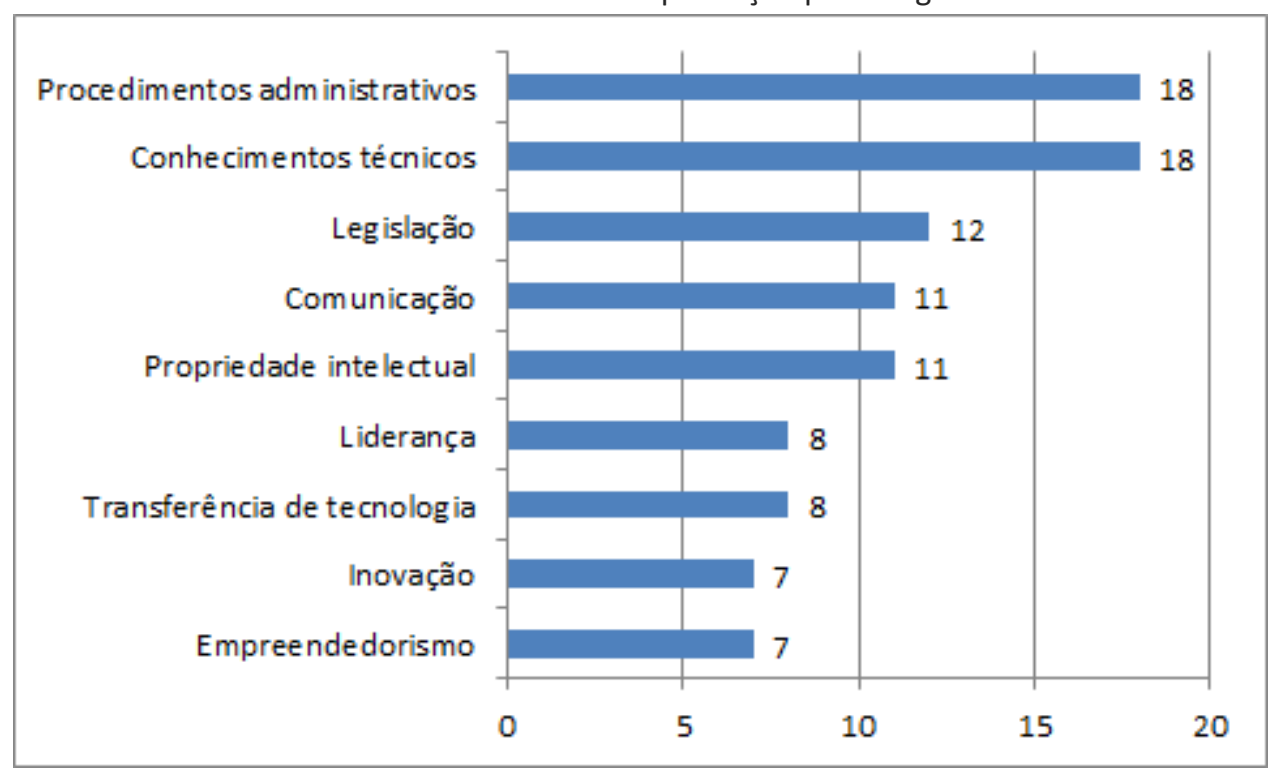

Fonte: Elaborado pelos autores.

Percebe-se que os itens empreendedorismo e inovação estão em últimos lugares, apesar de $68 \%$ dos pesquisados considerarem que a participação dos gestores em programas de qualificação para a atividade inovadora tem grande ou alto potencial de contribuição para a melhoria da gestão.

Cabe ressaltar que cursos nas áreas amplamente oferecidas como procedimentos administrativos e conhecimentos técnicos são fundamentais para que o gestor bem exerça suas funções. O que a pesquisa demonstra, no entanto, é que na área de inovação e empreendedorismo tais capacitações não são oferecidas na mesma escala.

Sobre a importância que os gestores atribuem a características relativas ao empreendedorismo, foram feitas duas perguntas.Na primeira, as características são relacionadas à gestão; na segunda, ao gestor público.

Onde se pretendia avaliar a importância que os respondentes davam às características empreendedoras na gestão pública, observou-se que elas são valorizadas pelos pesquisados em alto grau, o que se observa na Tabela 2 (onde as características foram colocadas na ordem decrescente, considerando a soma das opções "essencial" e "importante"):

Tabela 2 - Importância das características na gestão pública

\section{Essencial Importante}

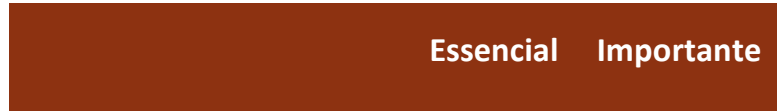

Estabelecer metas/objetivos

Trabalho em equipe
12

12
Pouco importante

Nada Indiferente 88

0

88
0
0

0 


\begin{tabular}{c|ccccc} 
& Essencial & Importante & $\begin{array}{c}\text { Pouco } \\
\text { importante }\end{array}$ & Nada & Indiferente \\
\hline Motivação & 68 & 32 & 0 & 0 & 0 \\
Visão sistêmica & 60 & 40 & 0 & 0 & 0 \\
Persistência & 48 & 52 & 0 & 0 & 0 \\
Liderança & 68 & 24 & 8 & 0 & 0 \\
\hline Criatividade & 32 & 60 & 8 & 0 & 0 \\
Busca por & 32 & 60 & 12 & 0 & 0 \\
oportunidades & & & & & \\
Flexibilidade & 40 & 48 & 12 & 0 & 0 \\
Espírito inovador & 40 & 48 & 8 & 4 & 0 \\
Correr riscos & 24 & 56 & 16 & 4 & 0 \\
\hline
\end{tabular}

Fonte: Elaborada pelos autores.

Correr riscos foi considerada a característica de menor importâncias dentre as elencadas. Estabelecer metas e objetivos e trabalhar em equipe, as mais valorizadas na gestão.

Estas características obtiveram $100 \%$ de respostas considerando-as como essenciais ou importantes: visão sistêmica, estabelecer metas e objetivos, trabalho em equipe, motivação e persistência.

A seguinte pergunta, sobre a importância que os respondentes davam às características empreendedoras na pessoa do gestor público ofereceu respostas similares, com alta valorização das características pelos pesquisados, de melhor observação por meio da Tabela 3, na qual as características estão na ordem decrescente, considerando a média ponderada obtida pela porcentagem de respostastas em cada grau:

Tabela 3 - Importância das características no gestor público

\begin{tabular}{ccc||ccccc} 
& $\mathbf{1}$ & $\mathbf{2}$ & $\mathbf{3}$ & $\mathbf{4}$ & $\mathbf{5}$ & Média \\
Trabalha em equipe & 0 & 0 & 0 & 20 & 80 & 4,80 \\
Eficiência & 0 & 0 & 0 & 24 & 76 & 4,76 \\
Comunicação aberta e frequente & 0 & 0 & 8 & 16 & 76 & 4,68 \\
Alcança resultados & 0 & 0 & 4 & 32 & 64 & 4,60 \\
Conhece o ambiente & 0 & 0 & 16 & 16 & 68 & 4,52 \\
legal/normativo & 0 & 0 & 8 & 36 & 56 & 4,48 \\
Gerencia conflitos & 0 & 0 & 4 & 44 & 52 & 4,48 \\
Gestão participativa & 0 & 0 & 12 & 32 & 56 & 4,44 \\
Bom relacionamento & 0 & 0 & 8 & 44 & 48 & 4,40 \\
Percebe novas oportunidades & 0 & 0 & 20 & 24 & 56 & 4,36 \\
Celeridade & 0 & 0 & 12 & 40 & 48 & 4,36 \\
Capacidade crítica & 0 & 4 & 16 & 28 & 52 & 4,28 \\
Busca recursos financeiros & 0 & 0 & 16 & 40 & 44 & 4,28 \\
Transforma adversidade em & & &
\end{tabular}




\begin{tabular}{ccc|cccc} 
& $\mathbf{1}$ & $\mathbf{2}$ & $\mathbf{3}$ & $\mathbf{4}$ & $\mathbf{5}$ & Média \\
\hline $\begin{array}{c}\text { oportunidade } \\
\text { Introduz novas ideias }\end{array}$ & 0 & 0 & 12 & 52 & 36 & 4,24 \\
Não se contenta com o status quo & 4 & 4 & 20 & 32 & 40 & 4,00 \\
Busca inovações & 0 & 12 & 20 & 36 & 32 & 3,88 \\
\hline Assume riscos & 4 & 4 & 20 & 48 & 24 & 3,84 \\
\hline
\end{tabular}

Fonte: Elaborada pelos autores.

Nota: A escala vai de 1 a 5, sendo que 1 é para irrelevante e 5 para essencial.

Novamente a capacidade de correr riscos foi considerada com menos importância entre todas as características.

A capacidade de trabalhar em equipe novamente foi a característica mais valorizada pelos pesquisados, seguida pela eficiência. Note-se que esta última é um dos princípios constitucionais que regem a Administração Pública.

Por fim, o questionário ofereceu aos pesquisados a opção de citar exemplos da aplicação de empreendedorismo e inovação em suas gestões. Os respondentes citaram: escuta ativa; trazer para a gestão conhecimentos adquiridos fora da instituição; participação de grupos externos de estudo; ajustes de regulamentos institucionais e modelos de cursos compatíveis com modelos e tendências mundiais; adequação das metodologias às mutações permanentes dos pefis dos estudantes e do setor produtivo; modelo participativo de gestão inter-campus; busca de processos de licitação de forma eletrônica; digitalização integral de processo do Conselho de Graduação para a celeridade e transferência dos trâmites; substituição de papel para a via digital, visando a sustentabilidade; inovação pedagógica; inovação em projetos de transferência de tecnologia.

\section{CONSIDERAÇÕES FINAIS}

O presente estudo discorreu sobre os conceitos e aspectos relacionados ao empreendedorismo, abordando um dos temas mais relevantes da atualidade, não só para as organizações que necessitam se tornar empreendedoras para sobreviver às contínuas mudanças da sociedade, mas para o próprio Estado, que pode concretizar seu desenvolvimento econômico, e consequentemente a equidade social e a democracia, por meio de uma gestão empreendedora.

Também apresentou os resultados da pesquisa sobre a investigação da percepção dos gestores da Universidade Tecnológica Federal do Paraná - UTFPR, quanto à importância do empreendedorismo no dia a dia da gestão de uma instituição pública de ensino superior, bem como a importância que os gestores atribuem a essas características.

No que tange às questões que pretendiam averiguar em que grau programas de empreendedorismo e inovação, eventos com alunos, eventos com servidores, NITs, cooperação com outras Universidades, cooperação com o setor privado, cooperação com órgãos de fomento, cooperação com a comunidade local, cooperação entre pesquisadores e pessoal administrativo de outras instituições, e cooperação entre pesquisadores e pessoal administrativo da própria instituição 
contribuem atualmente na gestão dos pesquisados e também qual o grau de contribuição que podem vir a ter, observou-se que a contribuição atual é inferior da que pode vir a ter para a gestão dos respondentes. Tal conclusão é possível porque, via de regra, os percentuais relativos ao potencial de contribuição foram bem mais elevados que aqueles sobre a contribuição atual dos itens elencados.

A despeito da importância dada pelos gestores em participar de programa de qualificação que favoreça a atividade inovadora, é possível perceber, pelas respostas obtidas na questão sobre os mecanismos de capacitação oferecidos pela instituição, que a qualificação em inovação e empreendedorismo é a menos propiciada dentre as alternativas oferecidas.

Dos Gestores pesquisados, $68 \%$ consideram que desenvolver habilidades na área de atividade inovadora tem grande ou alto potencial de contribuição para sua gestão, mas a capacitação em empreendedorismo e inovação é a menos oferecida pela instituição aos seus gestores.

Ressalte-se que a capacitação nas demais áreas é também fundamental para o bom desempenho dos gestores. Mas, considerando que a inovação é um processo gerido por administradores que devem ter habilidades para fazê-lo e que a capacidade para a gestão do processo de inovação pode ser aprendida, conclui-se que uma maior capacitação dos gestores em empreendedorismo e inovação pode ser capaz de maximizar suas atuações dentro da instituição, no desempenho de suas funções.

Nas questões envolvendo a importância das características inovadoras na gestão, os pesquisados consideram de importante a essencial todas as opções elencadas, em percentuais acima de $80 \%$, o que indica o elevado grau de importância que eles dão às características de uma gestão empreendedora.

Em relação aos atributos empreendedores considerados importantes num gestor público, os aspectos relativos ao empreendedorismo foram considerados, pelos pesquisados, importantes ou essenciais para um gestor público.

Pelo apresentado, é possível concluir que os gestores respondentes consideram importante na gestão pública e no gestor público a presença de características correlatas ao empreendedorismo, bem como percebem os atributos empreendedores na gestão administrativa da instituição em que atuam.

Também que as características relativas ao empreendedorismo, ao intraempreendedorismo e às organizações empreendedoras, são consideradas importantes, em elevados percentuais, pelos gestores pesquisados e estão presentes em sua atuação diária.

A qualificação dos gestores para a atividade inovadora, de uma maneira mais consistente, pode ser uma alternativa para fortalecer a presença das características empreendedoras na gestão da instituição onde atuam os pesquisados.

Nesse aspecto é relevante citar Feger, Fischer e Nodari (2009), sobre a possibilidade de se ensinar o empreendedorismo. Segundo os autores, apesar de não haver conclusão definitiva sobre o assunto, aumentam os indícios de que isso é possível, uma vez que os indivíduos tendem a sofrer influência do meio social onde vivem, inclusive quando se trata do desenvolvimento de comportamentos empreendedores. 
Além de outras que possam surgir a partir do presente estudo, propõe-se como possibilidade de pesquisas futuras, estudo da mensuração do desempenho empreendedor nas instituições públicas, responder com mais profundidade se programas de capacitação voltados à atividade inovadora podem contribuir de forma efetiva para uma gestão pública empreendedora. E, no caso de uma resposta afirmativa para esta segunda proposta, se esta gestão empreendedora pode levar a uma maior eficiência da Administração Pública no cumprimento de sua finalidade.

Por fim, considera-se que o objetivo da pesquisa foi alcançado. Averigou-se apercepção dos gestores quanto à importância do empreendedorismo no cotidiano de suas gestões, no exame de sua percepção quanto ao grau de importância que dão às características relacionadas ao empreendedorismo na gestão administrativa da organização em que atuam. 


\title{
Intrapreneurship in public sector: A case study in Technological Federal University of Paraná (UTFPR)
}

\begin{abstract}
With the social changes resulting from growing economic and cultural interdependencies that occur worldwide, entrepreneurship can contribute to the survival of organizations, including those of the public sector, favoring adding value to the services provided to society. Entrepreneurship has been little studied when it comes to the public sector, so that justifies the present study more accurate interpretations of the theme. The research aims to investigate the prospect of public officials about the importance of entrepreneurship in the management of a public organization. The research method used was a case study at the Federal Technological University of Paraná, with questionnaires to managers. The motivation to the choice of the subject matter, is the fact that universities are seen as institutions fundamental role in the process of teaching and disseminating entrepreneurship. The results showed the perspective of surveyed managers on the importance of characteristics related to entrepreneurship in public administration.
\end{abstract}

KEYWORDS: Entrepreneurship. Public intrapreneurship. 


\section{REFERÊNCIAS}

ACS, Zoltan, L.; STOREY, David J. Introduction: entrepreneurship and economic development. Regional Studies, v.38.8, p.871-877, nov.2004.

ALENCAR, Eunice M. L. S. Promovendo um ambiente favorável à criatividade nas organizações. Revista de Administração de Empresas, v. 38, n.2, p. 18-25, 1998.

BARON, Robert A.; SHANE, Scott A. Empreendedorismo: uma visão do processo. São Paulo: Cengage Learning, 2010.

CHIEH, Nelson; ANDRASSE, Tales. Intra-empreendedorismo: um estudo de caso sobre o entendimento e a aplicação dos fundamentos organizacionais associados ao termo. In: ENCONTRO ENANPAD, XXXI, 2007, Rio de janeiro.

CORRÊA, David P.; BÊRNI, Duílio A. O Conceito de Empresário Empreendedor Schumpeteriano e a sua Atualização. Análise: Revista Acadêmica da Face. Porto Alegre: PUCRS, 2000, v.11, n.2, p.21-48.

COELHO, Meire L. G. M. M. Intraempreendedorismo e a inovação na gestão pública federal.Revista do Serviço Público. Brasília, 2010, jul./set. 2010.

COSTA, Danilo M.; BARBOSA, Francisco V.; SILVA, Cláudio H. P. Empreendedorismo e inovação: o papel da educaçãosuperior nas economias mundiais. In: COLÓQUIO INTERNACIONAL SOBRE GESTÃO UNIVERSITÁRIA NA AMÉRICA DO SUL, XI. Florianópolis: IGLU, 2011. Disponível em: $<$ https://repositorio.ufsc.br/xmlui/bitstream/handle/123456789/32854/8.3.pdf? sequence $=1>$. Acesso em 25.06.2013.

DA COSTA, Alessandra M.; BARROS, Denise F.; CARVALHO, JosLúis F. RAC, Curitiba, v. 15, n. 2, art. 1, p. 179-197, mar./abr. 2011.

DAVID, Denise E. H.; CARVALHO, Hélio G.; PENTEADO, Rosângela S. Gestão de Ideias. Curitiba: Aymará, 2011.

DRUCKER, Peter F. A Administração na próxima sociedade. São Paulo: Nobel, 2002.

FEGER, José E.; FISCHER, Augusto; NODARI, Tânia M.Características empreendedoras de gestores públicos municipais: uma análise comparativa 
FILION, Louis J. Um roteiro para desenvolver o empreendedorismo.Tradução de: Fillion, L.J.; Lafetté, S. Carte routière pour un Québec entrepreneurial. Chaire d' entrepreneuriat Rogers - J.A.Bombardier. Raport remis au Gouvermement du Québec. HEC Montréal: Décember, 2003.

HASHIMOTO, Marcos. Organizações intraempreendedoras: construindo a ponte entre clima interno e desempenho superior. Tese de Doutorado - Fundação Getúlio Vargas, Escola de Administração de Empresas de São Paulo, Departamento de Administração. Orientador Prof. Doutor Tales Andreassi. Jun. 2009.

KLEIN, Peter G. et al. Towards theory of public entrepreneurship. European Management Review, 7, p.1-15, 2010.

LAGO, Adriano et al. Potencialidades e espaços ao empreendedorismo. Estudos do CEPE, 2008. Disponível em: <online.unisc.br/seer/index.php/cepe/article/ download/424/43>7>. Acesso em 25.06.2013.

LÉVESQUE, Benoîte. Empreendedor Coletivo e Economia Social: outra forma de empreender. Revista virtual de gestão de iniciativas sociais, n.2, fev-2005, p.4464.

LORETO, Fabiana; MAZZEO, Thais; MACHADO, Júlio C. Empreendedorismo corporativo: um estudo de caso o grupo Accor. Anais dos congressos de iniciação Científica da USCS. Disponível em: $<\underline{w w w . u s c s . e d u . b r / S i m p o s i o-}$ congresso/Congressoic/trabalhos.php?id=0406 \&area=humanas $>$. Acesso em 20.09.2013.

MATIAS-PEREIRA, José. Governança no Setor Público. São Paulo: Atlas, 2010.

MEZA, Maria Lúcia F. G. Empreendedorismo Público: discutindo seus níveis de análise.

SILVA, Christian L. da (org.) Políticas Públicas e Desenvolvimento Localinstrumentos e proposições de análise para o Brasil. Petrópolis, RJ: Vozes, 2012.

MIERLO, Hans J. G. A. V. Public Entrepreneurship as Innovative Management Strategy in the Public Sector. A Public Choice-Approach. 65Th Annual Conference of the Southern Economic Association Fairmont Hotel, New Orleans, Louisiana, United States of America. November 18-20, 1995. 
PAIVA JR, Fernando G.; GUERRA, José R. F. O empreendedorismo como marco solidário na esfera do desenvolvimento.Revista Gestão e Planejamento, Salvador, v. 11, n. 2, p. 267-276, jul-dez. 2010. Disponível em: $<$ http://www.revistas.unifacs.br/index.php/rgb/article/view/1255>. Acesso em 27.06.2013.

PINCHOT III, Gifford. Intrapreneuring: por que você não precisa deixar a empresa para tornar-se um empreendedor. São Paulo: Harbra, 1989.

PRADO, Maria de L.et al. Análise do perfil intraempreendedor de servidores de instituição de ensino superior; In: COLÓQUIO INTERNACIONAL SOBRE GESTÃO UNIVERSITÁRIA NA AMÉRICA DO SUL, XI. Florianópolis: IGLU. 2011. Disponível em:

$<$ https://repositorio.ufsc.br/bitstream/handle/123456789/26116/5.10.pdf?seque nce $=1>$. Acesso em 25.06.2013.

SALVI, Eloni J. et al.Comportamento intra-empreendedor nas empresas do Vale do Taquari. Salão de Iniciação Científica (19. : 2007 : Porto Alegre, RS). Livro de resumos. Porto Alegre : UFRGS, 2007.

SCHMIDT, Serje; BOHNENBERGER, Maria C. Perfil Empreendedor e Desempenho Organizacional Perfil Empreendedor e Desempenho Organizacional. RAC, Curitiba, v. 13, n. 3, art. 6, p. 450-467, Jul./Ago. 2009.

SOUZA, Eda C. L.; FRACASSO, Edi M.; LOPEZ JÚNIOR, Gumersindo S. Empreendedorismo e atitude empreendedora: conceitos e construção de escalas. In:ENCONTRO DE ESTUDOS SOBRE EMPREENDEDORISMO E GESTÃO DE PEQUENAS EMPRESAS, V., 2008,São Paulo.

TIDD, Joe; BESSANT, John; PAVITT, Keith. Gestão da Inovação. Porto Alegre: Bookman, 2008, cap.2.

TINOCO, João P. V. Empresas públicas de TIC: proposta de um modelo analítico para auxiliar a sua gestão com empreendedorismo público e alianças estratégicas. Tese de doutorado - Pontifícia Universidade Católica do Rio de Janeiro, Departamento de Administração. Orientadora: T. Diana L. V. A. de Macedo-Soares. 2012.

WOLF, Sérgio M. et al.Intraempreendedorismo em instituições de ensino público: o caso da Universidade Federal de Santa Catarina - UFSC. In: XI COLÓQUIO INTERNACIONAL SOBRE GESTÃO UNIVERSITÁRIA NA AMÉRICA DO SUL. Florianópolis: IGLU. 2011. Disponível em: <https://repositorio.ufsc.br bitstream/handle/123456789/26139/5.33.pdf?sequence=1 $>$. Acesso em 25.06.2013. 
Recebido: 28 jan. 2016.

Aprovado: 05 mar. 2016.

DOI: $10.3895 /$ rbpd.v5n1.3851

Como citar: MARQUES, S. B. V. et al. Intraempreendedorismo no setor público: Estudo de caso na

Universidade Tecnológica Federal do Paraná (UTFPR). R. bras. Planej. Desenv.,Curitiba, v. 5, n. 1, p. 26-

48, jan./abr. 2016. Disponível em: <https://periodicos.utfpr.edu.br/rbqv>. Acesso em: XXX.

Correspondência:

Sylvia Bitencourt Valle Marques

Rua Cardeal Arcoverde, 495, Jd. Seminário, Campo Grande, MS.

Direito autoral: Este artigo está licenciado sob os termos da Licença CreativeCommons-Atribuição 4.0

Internacional. 